\title{
La justice militaire et les civils sous le Directoire : l'exemple des $24^{\mathrm{e}}$ et $25^{\mathrm{e}}$ divisions militaires
}

Civil and Military Justice and Civilians under the Directory: the Example of the 24th and 25th Military Divisions

Xavier Rousseaux

\section{(2) OpenEdition}

\section{Journals}

Édition électronique

URL : https://journals.openedition.org/ahrf/11290

DOI : $10.4000 / a h r f .11290$

ISSN : 1952-403X

Éditeur :

Armand Colin, Société des études robespierristes

Édition imprimée

Date de publication : 1 décembre 2007

Pagination : 153-178

ISSN : 0003-4436

Référence électronique

Xavier Rousseaux, «La justice militaire et les civils sous le Directoire : l'exemple des $24^{e}$ et $25^{e}$ divisions militaires », Annales historiques de la Révolution française [En ligne], 350 | octobre-décembre 2007, mis en ligne le 01 janvier 2011, consulté le 01 juillet 2021. URL : http://journals.openedition.org/ ahrf/11290 ; DOI : https://doi.org/10.4000/ahrf.11290 


\title{
LA JUSTICE MILITAIRE ET LES CIVILS SOUS LE DIRECTOIRE \\ L'EXEMPLE DES 24'ET 25 DIVISIONS MILITAIRES*
}

\author{
Xavier ROUSSEAUX
}

En hommage à Jacques LOGIE (1938-2007)

\begin{abstract}
Pour rétablir l'ordre public troublé à la fois par le brigandage et les résistances à la Révolution, le Directoire recourut à diverses formes de juridiction militaire. Le recours à ces justices militaires pour réprimer des comportements attribués à des civils reste peu étudié même pour l'Ouest et le Midi. La contribution porte sur la pratique de ces juridictions dans le ressort des $24^{\circ}$ et $25^{\circ}$ divisions militaires, concernant les départements "belges " réunis le 9 vendémiaire an IV à la République. L'étude montre que le recours à ces juridictions, surtout aux conseils de guerre favorisés par la répression de la révolte de l'an VII, contribue à discriminer dans leur traitement les " révoltés " des "brigands " de droit commun. D'autre part, faire juger des civils par des juridictions militaires suscite des réticences tant de la part des autorités civiles que des autorités militaires. L'hypothèse est posée que l'expérience des départements "belges " contribua à la création de tribunaux criminels spéciaux intégrés à l'ordre judiciaire civil, mais composés de juges civils et de militaires.
\end{abstract}

Mots-clés : conseils de guerre, justice militaire, révoltes, brigandage, départements belges.

Dans son ouvrage récent, Ending the Revolution, Howard Brown propose une cartographie des places déclarées en état de siège entre septembre 1797 et décembre 1798. Celle-ci montre combien l'armée inter-

*Cette publication a été rédigće dans le cadre du Pôle d'attraction interunjversitaire P6/01, « Justice et société : histoire sociopolitique de la justice en Belgique (1795-20105) », Politique scientifique fédérale belge. 
vient essentiellement dans trois régions troublées : l'Ouest, le Midi et les départements belges. Notre contribution vise à étudier les rapports entre les civils et la justice militaire dans cette dernière zone'.

À la différence de l'Ouest et du Midi, où la répression s'inscrivait sur un fond d'oppositions violentes cristallisées depuis 1789-1790, les départements belges ne connurent les affrontements révolutionnaires pratiquement qu'après Thermidor. Après l'éphémère occupation de 1792-1793, les Pays-Bas autrichiens et les principautés ecclésiastiques de Liège et Stavelot sont reconquis en juillet 1794, au moment de la chute de Robespierre. L'an III correspond à une occupation militaire dans le contexte d'un débat sur la " réunion " à la France de la « Belgique ». Dès l'été 1794, des tribunaux dits « révolutionnaires », largement composés de militaires français y sont installés ; au printemps 1795, ils reçoivent des jurés locaux, tandis que les comités de surveillance, souvent émanés des milieux jacobins, sont supprimés?

Quelques semaines après le vote de la Constitution de l'an III, la réunion des départements belges à la France est proclamée parmi les derniers actes de la Convention (9 vendémiaire an IV-1" octobre 1794). Du point de vue administratif et judiciaire, ces régions « reçoivent » progressivement les lois ${ }^{3}$, le découpage territorial en neuf départements et l'architecture judiciaire élaborée par les Thermidoriens". À Bruxelles et Liège, les deux capitales des anciens États, les tribunaux criminels s'inscrivent dans le droit fil des tribunaux dits « révolutionnaires » 5 .

Ces neuf départements constituent de ce fait un bon laboratoire pour étudier plusieurs phénomènes cruciaux au tournant des XVIII" et $\mathrm{XIX}^{\mathrm{e}}$ siècles sur le plan local, mais également pour examiner la spécificité de la période de thermidor an II à brumaire an VIII", ou pour situer les caractéristiques originales de l'histoire politique française dans le concert européen : la modernisation d'une monarchie absolutiste en État-Nation'.

(1) Howard Brown, Ending the French Revolution Violence, Justice and Repression, from the Terror to Napoleon, Charlottesville/London, University of Virginia Press, 2006, fig. 10, p. 210.

(2) Xavier RousseAuX, « De la justice révolutionnaire à la justice républicaine : le tribunal criminel de Bruxelles (1794-1795)", dans La Révolution et l'ordre juridique privé : rationalité ou scandale ? Actes du colloque d'Orléans 11-13 septembre 1986, Paris, PUF, 1988, t. 2, p. 527-540.

(3) Fred StLvens, "Lintroduction de la législation révolutionnaire en Belgique ", dans La Révolution et l'ordre juridique privé, op. cir., t. II, p. 485-493.

(4) Xavier RoUsSEAux, “ Une architecture neuve pour la justice des pays conquis. Lorganisation judiciaire et la procédure pénale (1789-1815) ", dans Xavier RoUsSEAUX, Maric-Sylvic DuPONT-Bouchat, Claude $V_{\mathrm{AEL}}$, dir., Révolutions et Justice pénale en Europe (1780-1830). Modèles français et traditions nationales, Paris, L'Harmattan, 1999, p. 37-58.

(5) Voir Xavier Rousseaux, " De la justice révolutionnaire à la justice républicaine, ", op. cit.

(6) Voir Michel Vovfl.LE, dir., Le toumant de l'an III. Réaction et Terreur blanche dans la France révolutionnaire, Paris, Éd. du CNRS, 1997 ; Philippe Bourdin et Bernard GAinot, dir., La République Directoriale. Actes du colloque de Clermont-Ferrand (22-24 mai 1997), 2 vol. Paris, SER, 1998 ; Jean-Pierre JESSFNNF et al. , dir., Du Directoire et Consulat, 4 vol.. Lille, CRHENO, 1999-2001.

(7) Par Etat national, on reprend la distinction établic par Charles Tit.ty, dir. The Formation of National States in Western Europe, Princeton, Princeton University Press, 1975. Celui-ci distingue l'ÉtatNation où l'État et la Nation coïncident et les États nationaux où l'État transcende ou articule différentes nations. 
Dans cette période cruciale pour la formation d'un État-Nation, les pratiques judiciaires apparaissent un lieu d'observation fondamental. Le débat a débuté avec l'usage " révolutionnairc " des juridictions criminelles ordinaires au moment de la Terreur. Au-delà du modèle parisien du Tribunal révolutionnaire, de nombreuses recherches ont souligné la diversité des moyens utilisés au plan local, en fonction de l'âpreté des oppositions entre partisans et adversaires des factions dominantes ${ }^{8}$. Plus récemment, les relectures de la période directoriale ont mis en évidence la complexité des relations des autorités à la violence, surtout après le discrédit des " terroristes " vre autoritaire, le régime directorial se caractérise par une diversité de manières d'intégrer l'extraordinaire dans la justice ordinaire (commissions militaires ad hoc, conseils de guerre, loi des otages).

Dans les pratiques judiciaires, le recours à l'armée pour « rétablir » ou créer un " ordre public " pose une séric de questions fondamentales sur les liens entre justice et politique : dans l'appréciation du caractère politique des conflits (révolutionnaires et contre-révolutionnaires) et l'évaluation de la « terreur directoriale " à l'aune de l'expérience des terreurs précédentes (petite, grande, rouge, blanche...); dans la mesure du contrôle de la violence légitime, qui est une condition essentielle de légitimité d'un État moderne ; dans l'évaluation plus globale de l'équilibre entre justice d'exceptionnalité (tâche assignée traditionnellement par la doctrine aux justices militaires) et justice ordinaire véhiculant le modèle de la révolution pénale de 1790 , empreinte des idéaux des Lumières.

\section{La justice militaire sous la Révolution}

Si les recherches sur la justice militaire sous le Consulat et l'Empire existent $^{10}$, elles ne sont guère nombreuses pour la Révolution". Plusieurs recherches concernent essenticllement son activité en matière de discipline militaire ${ }^{12}$, ou s'inscrivent dans un courant d'histoire de la délin-

(8) Robert AlLen, Les tribunaux criminels sous la Révolution et l'Empire 1792-1811, Rennes, PUR. 2005 .

(9) Jean-Clément MARTIN, Violence et révolution. Essai sur la naissance d'un mythe national, Paris, Le Seuil, 2006.

(10) Jean-Louis Gazzaniga, “ Les conseils de guerre de la $10^{\circ}$ Division sous le Consulat et l'Empire : la justice aux armées de l'intérieur ", Revvé de science criminelle ce de droit pénal comparé. 1978, $n^{\circ}$ 1, p. 61-81 ; Cécile DouxChamps-LeFÉVRE, "Jugements des conseils de guerre spéciaux de la Grande Armé à charge de conscrits du département de Jemappes 1806-1809 ", Revue du Nord, $\mathrm{n}^{\circ} 229$, avril-juin 1976 , p. 235-243.

(11) Georges Micion, La justice militaire sous la Révolution, Paris, Alcan, 1922 ; Bernard SCHNAPPER "Le droit pénal militaire sous la Révolution : prophétisme ou utopie ?", dans Travaux de l'Institut de Sciences criminelles de Poitiers, 5,1986, p. 1-13.

(12) Louis Henneouin, La justice militaire et la discipline à l'armée du Rhin et à l'armée de Rhin-etMoselle (1792-1796). Notes historiques du chef de bataillon de génie Legrand, Paris, Chapelot, 1909 ; Georges Michon, « La justice militaire sous la Convention, à l'armée des Pyrénées-Orientales „, AIIRF, 1926, p. 37-46; 
quance militaire $^{13}$. Lutilisation des juridictions militaires envers des civils fait l'objet de peu de recherches ${ }^{14}$, sinon indirectement à travers la vaste littérature sur le brigandage et le banditisme.

Or, après la Terreur, où les institutions civiles servirent de bras armé à la répression politique, la justice militaire offrit tout naturellement au gouvernement une voie alternative pour cette dernière. Graduellement les Thermidoriens raffinèrent l'usage de la justice militaire pour traiter les comportements perçus comme menaçants pour le régime sans écorner trop l'idéologie de la protection du citoyen devant la justice ordinaire ${ }^{15}$. Le Directoire continua dans cette politique de maintien simultané de droits pour les accusés et du recours aux juridictions militaires régulières.

On ne peut donc comprendre l'utilisation des conseils de guerre du Directoire qui font l'objet de notre recherche, sans étudier leur filiation avec les commissions militaires établies par le Directoire le 19 fructidor an $\mathrm{V}$, et en perdant la mémoire des «commissions militaires » de l'an II et III ${ }^{17}$.

\section{Les tribunaux criminels militaires}

Dans les départements « belges », durant la période de conquête, les tribunaux criminels militaires sont actifs. Ainsi, à Nivelles, à la fin de l'an II, le « tribunal criminel militaire et révolutionnaire établi près de l'armée de Sambre-et-Meuse " condamne-t-il à la peine de mort quatre militaires pour des pillages commis à l'abbaye de la Cambre ${ }^{17}$. Outre leurs compétences sur les militaires, ces tribunaux jugèrent également des civils capturés par l'armée. Ainsi, le 10 fructidor an II, la deuxième section du Tribunal criminel militaire est assemblée pour juger " révolutionnairement " Joseph Pierrard, habitant du pays de Limbourg, Guillaume Blairet natif de Liège, Marie Thérèse Guetkin, Marie Jeanne Pirlot et Jeanne Laurence, accusés d'avoir « des intelligences avec l'ennemi ». Le premier est porteur d'un

Frédéric MAcuin, La justice militaire et la désertion à l'armée de Sambre-et-Meuse en lan V, mémoire de man̂trise, Histoire, Paris I, 1999, dact. ; Céline CARC 'Et.F., La justice militaire à l'armée du Nord en l'an IV et l'an V, mémoire de maîtrise, Histoire, Paris I, 1997, dact. Philippe STurmbl, Justice ef discipline militaires sous la Révolution et l'Empire. La dixième division militaire, thèse de doctorat, Histoire du droit, Toulouse I, 1998.

(13) Jean CavignaC, « La délinquance militaire dans la région de Bayonne (1797-1805) ", Bayonne et sa région. Actes du 33. Congrès de la Fédération historique du Sud-(uest, Bayonne, 1981-1982, n. sér. 137-138, p. 317-335.

(14) Damien LAugier, Les civils devant la justice militaire sous le Directoire dans le Nord, mémoire de DEA. Théoric du droit et de sciences judiciaires, Université de Lille II, 1996, dact.

(15) Howard BRown, Ending the French Revolution..., op. cit., p. 141.

(16) Voir notamment le rôle du procès Carrier dans le discrédit des commissions militaires, Jacques Dupaquier, "Le procès de Carrier ", dans Michel Vovelle, dir., op. cit., p. 27-34.

(17) Archives de la ville de Bruxelles (AV Bruxelles), Archives Anciennes (AA), L 455 exécuteur des hautes ceuvres, extrait du registre des jugements du tribunal criminel militaire et révolutionnaire établi près de l'armée de Sambre-et-Meuse, 22 messidor an II. 
passeport, le deuxième correspond avec le chevalier Daunay émigré de Liège dont il est l'intendant. N'ayant pu " acquérir des preuves assez convainquantes " contre les cinq suspects, le tribunal remet en liberté Pirlot et Laurence et ordonne la détention dans les prisons de Bruxelles de Pierrard, Guetkin et Bléré « pendant tout le tems que les armées de la République occuperont le territoire du pays de Liège $»^{1 x}$.

\section{Les commissions militaires provisoires}

Des commissions militaires avaient été tout d'abord chargées, par la loi du 25 brumaire an II, de juger les émigrés pris dans des rassemblements armés ou non. Elles furent ensuite établies, notamment dans l'Ouest, pour lutter contre les Chouans. Ces commissions étaient établies ad hoc, la procédure militaire était accélérée, l'exécution des peines capitales immédiate ou dans les 24 heures. Pas question d'appel, de révision et de cassation.

Dans la fouléc du coup d'État du 18 Fructidor, la loi du 19 fructidor an V (5 septembre 1797) instaura le serment de haine à la royauté, et rétablit les lois anti-émigrés de 1792-1793. Les commissions militaires, composées de cinq officiers, étaient chargées de vérifier l'identité des émigrés inscrits sur la liste officielle et de leur appliquer la peine de mort dans les 24 heures $^{19}$. La loi du 21 fructidor prévoyait un recours en cassation possible pour incompétence de la commission ${ }^{20}$. Lenquête d'Howard Brown conclut qu'entre vendémiaire an VI et fructidor an VIII, « les commissions militaires siégèrent dans 50 cités et villes différentes, et rendirent 1006 jugements à l'encontre de 975 individus. Ces jugements comprenaient la condamnation de 274 individus à mort, 93 à la déportation, 24 à l'exil et 22 à des peines d'emprisonnement ${ }^{21}$. Certaines commissions ont fait l'objet de travaux approfondis ${ }^{22}$; avec Howard Brown, remarquons ici que le profil des individus jugés était bien plus large que le binôme noble-ecclésiastique émigré. On y trouve des artisans et des ouvriers.

(18) Ibid., 10 fructidor an II.

(19) Howard BRown, " Mythes et massacres : reconsidérer la " terreur directoriale " ", $A H R F$, $2001, n^{\circ} 3$, p. 23-52.

(20) Jacques BOONE, "In naam van het Franse volk ": Twee " kapitcins van de opstandelingen ", Pieter Corbeels en Albert Meulemans voor de krijgstaad [ "Au nom du peuple français " : deux " capitaines des révoltés ", P.C et A.M. devant le conseil de guerre], I, Taxandria, 1997, 69, p. 59-123; II, Tuxandria, 2005, 77, p. $5-110$ (p. 59).

(21) Howard Brown, « Mythes et massacres... ", op. cit., p. 26-27.

(22) Jean-Maric Aucjusis, "Les Vendéens devant la Commission militaire de La Rochelle ", dans la Rochelle, ville frontière, actes du Colloque du 28 et 29 avril 1989 à la Maison de la Culture de La Rochelle, Ville de lat Rochelle et Rumeur des Äges, 1989, p. $209-222$; Constant Friconneau, "La Commission militaire des Sables-d’Olonne pendant la Révolution ", Olona, 1985, n" 111, p. 25-35; Alfred Jamaux, "La commission militaire O'Brien [à Saint-Malol ", Annales de la Société d'histoire et d'ar. chéologie de l'arrondissement de Saint-Malo, 1996, p. 207-226; Albert PIIILIPPON, " La promic̀rc Commission militaire dite Commission Senar (23 juin-17 juillet 1793) », Bulletin trimestriel de la Société archéologique de 
De telles commissions fonctionnèrent également dans les départements fraîchement réunis. Ainsi à Liège (département de l'Ourthe), Léonard Chindelair, un nommé Jarbeau, Marque, Prons Philippe Simon, et Louis-Eugène Mathy, prévenus d'émigration comparaissent devant une commission militaire, et sont condamnés à mort et guillotinés en l'an $\mathrm{VI}^{23}$. Un certain flou existait cependant dans les pratiques, car à la même époque, les nouveaux tribunaux criminels de département de la Dyle à Bruxelles et de l'Ourthe à Liège jugent également des émigrés... À Bruxelles, le 22 thermidor an IV, six individus sont exposés puis guillotinés pour émigration, suite à jugement d'une commission de l'armée du Nord $^{24}$. Ces commissions semblent disparaitre, hormis un cas en germinal an VII, où, dans le contexte de la "guerre des paysans ", une commission militaire du $5^{\circ}$ régiment de dragons aurait condamné à mort Henri Joseph Nuewens, de Bruxelles, ancien notaire ${ }^{25}$.

\section{Les conseils militaires et la loi du 22 messidor}

En marge de la réactivation des « commissions militaires » visant les émigrés, la justice militaire dans son ensemble fait l'objet d'une profonde transformation sous la Convention. Constatant la faillite du système des tribunaux militaires avec jury, la loi du $2^{\mathrm{c}}$ jour complémentaire de l'an III (18 septembre 1795) abolit ces tribunaux au profit de conseils militaires. A la place d'institutions permanentes dotées de juges élus et de jury, sur le modèle des institutions civiles, les conseils militaires formés de neuf militaires et mis sur pied de manière temporaire s'avèrent redoutables pour les civils soumis à leur jugement. Dans l'Ouest ou le Midi toulousain, les conseils militaires appliquèrent la loi du 30 prairial an III, leur permettant de juger " chouans et révoltés "; de manière extensive, car la loi permettait de juger non seulement les rebelles saisis sur le champ, mais aussi les suspects capturés en-dehors des combats.

Touraine, 29, 1-2, 1944-1946, p. 75-135 ; Id., " La deuxième Commission militaire, Tours, novembre 1793mai 1794 ", Bulletin trimestriel de la Société archéologique de Touraine, vol. 34, 1967 (1966), p. 417-466 Raymonde MONNIFR, "Justice d'exception et justice militaire : l'exemple de la " Commission militaire du Temple " de fructidor an IV ", dans La Révolution et l'ordre juridique privé..., op. cit., tome II, p. 707-722.

(23) Le premier en vertu des articles 16 et 18 de la loi du 19 fructidor et de l'article 2 du titre 4 de

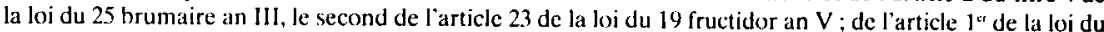
20 fructidor III, et de l'article 11 de la section I du titre 4 de la loi du 13 brumaire an V. Vincennes, Service historique de la Défense (SHD), 2J 308, 25. DM, $\mathbf{n}^{\circ} 3054,3055$, Commission militaire de Liège 25 et 20 pluviôse an VI. Voir Howard Brown, « Mythes et massacres... ", op. cit., p. 47. Georges de FroidcourT, La guillotine liégeoise ét les exécuteurs des arrêts criminels, Liège, Thone, 1934, p. 34-35.

(24) AV Bruxelles, AA, L 455, lettre de l'adjudant-général Leclere chef d'État-Major de l'Armée du Nord $24^{\circ}$ DM, à la municipalité de Bruxelles; 21 thermidor an IV.

(25) SHD, 2 J 295, jugement du 12 germinal an VII place de Gand, $n^{\circ} 28077$. Cité par Jacques BOONE, «In naam... ", op. cit., II, 2005, p. 60. Comme il s'agit d'un jugement pour émigration, il peut s'agir d'une commission « loi de fructidor ». 
Dans les « départements belges ", ces conseils temporaires intervinrent contre les "brigands contre-révolutionnaires ». Suite à des troubles survenus au sud de Bruxelles et attribués aux menées contre-révolutionnaires de Charles Jacquemin, dit Charles de Loupoigne, une échauffourée entre soldats et paysans se produit à Genappe (Dyle) les 14 et 15 nivôse an IV ; le général Songis envoie une colonne ratisser les villages avoisinants. Plusieurs individus sont arrêtés suite à cette opération ; la question se pose de savoir quelle juridiction est compétente à leur égard. Le 17 nivôse an IV (7 janvier 1796), le substitut du commissaire du pouvoir exćcutif du tribunal criminel signale au ministre de la Justice que « le conseil militaire a ordonné et fit exécuté [sic] de suite neuf condamnés par son jugement à être fusillés. Je suis bien loin d'approuver, que le tribunal criminel dont je fais partie ait avant mon arrivée et dès son institution, ordonné un pareil supplice, et qu'il ait eu lieu [...] $"^{26}$. Le lendemain, le commandant de la place exige de la municipalité que soit « envoyé le plus matin possible un crieur et un ou deux afficheurs pour faire publier leur jugement " et que soit « rendu sur la place de la liberté [la Grand'place] deux voitures pour y prendre les cadavres et indiquer un endroit où ils seront enterrés en faisant faire leur fosse $\gg^{27}$.

Laccusateur public du tribunal criminel de la Dyle est saisi d'une demande du général Songis d'avoir copic de la procédure envers une série de paysans arrêtés. Le tribunal accepte mais se réserve le droit de les juger $^{28}$. Le 15 pluviôse an IV, l'accusateur public du tribunal criminel de la Dyle écrit au ministre de la Justice : « le général Songis me manda qu'il venoit de recevoir une dépêche du citoyen Bouteville Commissaire de gouvernement [pour les départements réunis], relative a cette même procédure, que pour confirmer il alloit nommer une commission militaire [...] ». Laccusateur public ajoute qu'il « paroit au citoyen Lambrechts très certain que le conseil militaire est compétent. Il n'est pas douteux que ces individus ou ont pris les armes pour l'Empereur [d'Autriche] ou sont instigateurs de ce rassemblement armé ». Le 27 pluviôse an IV, six individus sont condamnés par cette " commission militaire » suite aux événements de Genappe. Parmi eux, cinq civils. Trois d'entre eux sont condamnés à trois mois de détention, un à cinq ans de fers et le dernier, Antoine Lecocq, " convaincu d'avoir approvisionné par ses soins la bande insurgée ", et d'être " de la confidence intime du chef Charles Jacqumin [sic] » est condamné à mort ${ }^{20}$.

(26) AN, BB18/283 Dyle, 17 nivôse an IV.

(27) AV Bruxelles, AA, L 455 exécuteur des hautes cuvres.

(28) Anderlecht, Archives de l'État (AE Anderlecht), Tribunaux criminels de la Dyle et cour d'assises de Brabant, 171, $n^{\circ} 15,12$ pluviôse IV.

(29) Remarquons la confusion entretenue dans la correspondance entre commission et conseil militaire. Or, en fonction des peines prononcées, il s’agit bien de conseils militaires prévus par la loi du 22 messidor et non de commissions militaires exceptionnelles. 
Le 6 ventôse an IV, un conseil militaire de la place de Bruxelles " légalement assemblé par ordre du général Tilly commandant les neuf départemens réunis ", juge par contumace "Charles Jacquemin soidisant Cousin Charles de Loupoigne et dom Guillaume Chantine proviseur de l'abbaye de Villers pour instigations et actes contrerévolutionnaires, tendants à faire renaître la Royauté et le pouvoir monacale [sic] éteints dans ces pays par l'entrée glorieuse des Français en formant une armée par le moyen du tocsin, à effet de chasser les français de la Belgique "; ils sont par contumace condamnés à la peine de mort en vertu de la loi du 30 prairial et $2^{c}$ jour complémentaire an III $^{36}$. Le jugement est affiché sur la Grand'place de Bruxelles le 7 ventôse". Le 6 germinal an IV, Jean Baptiste Lockx et Gilles Daniels, « tous deux prévenus de s'être portés sur les grandes routes attenantes à la forêt de Soigne ou ils ont exercés étant en bande armés des vols avec violence " comparaissent devant un conseil militaire. Constatant l'impossibilité de faire paraître les témoins à la décharge de Lockx, le conseil " le renvoie à un autre conseil qui sera convoqué au moment où il aura été signifié aux dits témoins de paraître ». Sur les conclusions du capitaine rapporteur, le conseil condamne Daniels « en son âme et conscience à la peine de seize années de fers et à être exposé à la vue publique sur la Grande place pendant six heures $»^{32}$. S'il ne mentionne pas la loi appliquée, le conseil condamne bien à des peines du Code pénal, qui seront exécutées selon les modalités des exécutions criminelles ordinaires.

De son côté le tribunal criminel de la Dyle annule la procédure contre cinq autres accusés pour les mêmes troubles, les renvoie devant le directeur du jury de l'arrondissement intérieur de Bruxelles. Ils seront finalement acquittés le 30 ventôse an $\mathrm{V}^{33}$.

\section{Les conseils de guerre permanents}

Le 13 brumaire an V ( 3 novembre 1796), les "conseils de guerre " remplacent les " conseils militaires ". Structures permanentes installées dans chaque division militaire, ils sont composés d'officiers. Ils sont principalement chargés d'appliquer le nouveau code de justice militaire du 21 brumaire an V (11 novembre 1796) ${ }^{74}$. Ces conseils étaient prévus jusqu'à la paix. En fait, l'institution servira de base à la justice militaire française. En temps de paix, la compétence était strictement limitée aux infractions

(30) AV Bruxelles, AA, L 455, exécuteur des hautes ceuvres, copie du jugement du 6 ventose an IV. (31) Ibid., lettre du commandant amovible de la place de Bruxelles à la municipalité de Bruxelles, 7 ventôse an IV.

(32) Ibid., copie du jugement du 6 germinal an IV 30 ventôse an $\mathrm{V}$

(33) AE Anderlecht, Tribunaux criminels de la Dyle et cour d'assises de Brabant, 172, $n^{\circ} 238$,

(34) Le 4 fructidor an V, une loi complémentaire organisait ces conseils de guerre. 
de nature militaire commises par des militaires (désertion, insubordination et infractions de droit commun - violences et vols) à l'intérieur de l'armée. En temps de guerre et hors des frontières, il était prévu que toutes les infractions commises par les militaires relèvent des juridictions militaires, ce qui se manifesta sous le Directoire tout particulièrement dans les régions conquises ${ }^{35}$.

Mais les conseils de guerre jugèrent un autre public et furent utilisés dans la luttc pour créer un ordre public, en particulier contre les formes de criminalité collective (révoltes chouannes, brigandage, banditisme, vol en bandes à main armée). Et c'est particulièrement le Directoire qui recourut à cette juridiction pour pacifier les campagnes.

\section{L'activité des conseils de guerre permanents des $24^{*}$ et $25^{\mathrm{e}}$ divisions militaires (1796-1802)}

De ventôse an $\mathrm{V}$ jusqu'en vendémiaire an XII, les conseils de guerre de la $24^{\circ}$ et de la $25^{\circ}$ divisions militaires prononcèrent plus de 1800 jugements contre des civils. Ils furent le vecteur principal de la répression des survivants des troubles paysans, que l'historiographie belge a baptisé du nom de "Guerre des paysans " ${ }^{360}$ et pour le Luxembourg de "Guerre des gourdins " ou "Kleppelkrick " réunis à l'automne 1798. Mais à y regarder de plus près, leur activité ne se limite pas à la traque des rebelles. Ces conseils jugent également près de 300 « brigands » dont les jugements ne témoignent d'aucune activité politique, mais d'une série d'opérations de « chauffage » et garrottage.

Événement traumatique, la "Gucrre des paysans » a donné lieu à deux siècles de constructions mémorielles dans le cadre de la formation d'un État national, issu en 1830 des conséquences du Congrès de Vienne : la Belgique. Monuments, œuvres littéraires, débats idéologiques enserrent

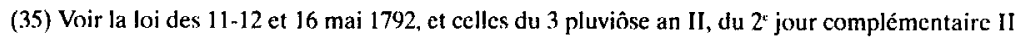
et 13 brumairc an $\mathrm{V}$.

(36) Parmi les travaux de synthèse récents, voir Marie-Sylvie Duponr-Bouchar, « Les résistances à la Révolution. La Vendée belge : nationalisme ou religion?", dans Roland MOrritk et Hervé HasquiN, dir., Deux aspects contestés de la politique révolutionnaire en Belgique: langue êt culte, Litudes sur le XVIII siècle, t. XVI, Bruxclles, éd. ULB, 1989, p.11\%-164; Fred Sievtins, "La résistance au Directoire dans les départements réunis. La "Guerre des Paysans" (octobre-novembre 1798) ", dans Philippe Bourdin et Bernard GaINOT, dir., op. cit., p. 1025-1045; Xavier RoussEAUX, "Rebelles ou brigands ? La " gucrre des paysans " dans les départements "belges " (octobre-décembre 1798) ", Cahiers dhistoire. Revue d'histoire critique, $\mathrm{n}^{\circ}$ 94-95, 2005, p. 101-132.

(37) Gilbert TkAUsch, " Les soulèvements de 1798 dans la région de Neufchâteau et leurs répercussions dans le département des Forêts ", Publications de la Section historique de l'Institut grand ducal de Luxembourg, 1962, 79, p. 65-133;/dem, a À propos du Klepclkrich. La répression des soulèvements paysans de 1798 dans le Département des Forêts (aspects et problèmes) ", Publications de la Section historique de I'Institut grand ducal de Luxemboung, 1967, 82, p. 11-245 ; Idem., " Die Luxemburger Baueraufstände aus dem Jahre 1798. Der "Klöppelkrieg ", seine Interpretation und sein Nachleben in der Geschichte des Grossherzogtums Luxemburg ", Rheinische Vierteljahrbläter, 1984, 48, p. 161-237. 
la représentation des événements ${ }^{38}$. En ressort une vulgate privilégiant la figure nationaliste du jeune paysan, soutenu par sa communauté villageoise, défendant sa religion catholique contre la République sans Dieu, héroïque victime des Sans-culottes. Cette «vision des vaincus » a tendance à masquer les différentes facettes du recours à la violence pour assurer la domination du régime républicain dans ces territoires nouvellement « réunis ». L’analyse de la répression montre en effet la complexité des moyens employés.

La violence militaire tout d'abord ; le recours à la détention policière, aux otages et à la déportation administrative ensuite. L'usage des juridictions ordinaires civiles (tribunaux de première instance) et pénales (tribunaux de police correctionnelle et tribunaux criminels) pour sanctionner les communautés et les individus et le renvoi aux juridictions militaires pour juger les participants saisis sur le champ des conflits. Après la violence des combats (environ 5000 morts en octobre-décembre 1798), la justice militaire fut le second pourvoyeur de la répression. Lanalyse des jugements des conseils de guerre conservés à Vincennes apporte des éléments neufs sur les procédures et les acteurs de cette répression judiciaire ${ }^{31}$, en particulier sur le face-à-face entre civils et militaires dans un contexte de résistances à l'État.

\section{Civils devant des juridictions militaires : le dispositif normatif}

Une première extension des compétences des conseils sur des personnes étrangères à l'armée est introduite par la loi organique du 13 brumaire an $\mathrm{V}$ qui prévoit le jugement des embaucheurs et espions par les conseils de guerre (art. 5) ${ }^{41}$. Déjà, par la loi du 30 prairial an III (18 juin 1795), introduite à l'occasion de la résurgence des troubles dans l'Ouest, définit le « rebelle » et distingue les « chefs et instigateurs » des « habitants des campagnes, entraînés et surpris dans des rassemblements ${ }^{41}$. Cette loi

(38) Pour suivre ces différents débats en histoire et mémoire, nous renvoyons le lecteur à la contribution de Maric-Sylvic Dupon]-Bouchat, Xavier Rousseaux et Fred Stevens, "La guerre des paysans (1798). Mythes et réalités. Brigandage, révolte nationale ou croisade religieuse? ", dans Laurence VAN YPERSELE, dir., Imaginaires de Guerre : l'histoire entre mythes et réalités, Louvain-la-Neuve, Presses Universitaires de Louvain, 2003, p. 53-89 ; Philippe RaxuON. La mémoire de la Révolution française. Entre Liège et Wallonie, Bruxelles, Labor, 1996 ; Jan Goris, Fred StEVEns, Karcl Veraghtert et Marcel Gielss, Voor Outer en Heerd, 1798. De Boerenkrijg in de Antwerpse Kempen, Brepols, 1998 [Pour le foyer et l'autel. 1798. La guerre des paysans dans la Campine anversoisc ]: Luc Françors, De Boerenkrijg. Twee eeuwen feiten en fictie, Leuven, Davidsfonds, 1998 [La guerre des paysans. Deux siècles de faits et de fiction].

(39) Létude systématique de la répression est en cours. Les premiers éléments d'analyse ont été présentés dans Xavicr Roussliaux, "Rebelles ou brigands ?... ", op. cit., p. 101-132 et dans Idem., "Rebels or Bandits? Representations of the "Peasants' War" in Belgian departments under French rule (1798)", dans Amy G. SREBnick, René LÉvY, dir., Crime and Culture. An Historical Perspective, Aldershot, Ashgate, 2005, p. 163-181. les espions.

(40) Cette disposition reprenait les dispositions antérieures contre les recruteurs pour l'ennemi et

(41) Loi du 30 prairial an III, article 1, 2 et 5. 
fut confirmée par le décret du $1^{\text {er }}$ vendémiaire an $I V^{42}$ et la loi du 3 brumaire an IV (25 octobre 1795), révisant le Code pénal de 1791 dans son article 598. Le code confirma le maintien de la peine de mort envers tout acte de conspiration contre la République ${ }^{43}$. À côté de ces dispositifs orientés vers les contestations «politiques", les lois spéciales du 26 floréal an V (15 mai 1797) et surtout du 29 nivôse VI (18 janvier 1798) renforcèrent la répression contre le banditisme ${ }^{44}$. Ces deux textes introduisirent explicitement le concept de criminalité collective dans la législation de la Révolution, que le Directoire allait préciser, à commencer par la loi du 26 floréal an V (15 mai 1797)

Suite au message du Directoire du 11 frimaire an $V$ « pour obtenir des mesures contre les voleurs signalés sous le nom de chauffeurs ", un projet fut finalement approuvé après trois lectures, le 26 floréal. Réalisé dans l'urgence et assez vague, le texte renforçait la répression des crimes prévus par les articles 2 et 3 de la $2^{\mathrm{c}}$ section du titre 2 de la $2^{\mathrm{c}}$ partie du Code pénal de 1791. Visant les crimes commis à force ouverte dans les maisons, il prévoyait la peine de mort pour tous les coupables, mêmes ceux trouvés sans armes, dans les cas suivants : $1^{\circ} \mathrm{Si}$ lcs coupables se sont introduits dans la maison par la force des armes. $2^{\circ} \mathrm{S}$ 'ils ont fait usage de leurs armes, dans l'intérieur de la maison. $3^{\circ} \mathrm{Si}$ les violences exercées sur ceux qui se trouvaient dans la maison ont laissé des traces, telles que blessures, brûlures ou contusions. En punissant de mort les auteurs d'agressions armées en groupe, la loi précisait la notation de criminalité collective (le banditisme au sens strict) ${ }^{40}$.

La loi du 29 nivôse an VI, quant à elle, est issue d'un projet présenté par le député Roemers au Conscil des Cinq-Cents, ; le projet entraîna des craintes dans l'assemblée comme dans l'opinion. Le Journal des débats rapporte que «le nom seul de commission militaire fut une cause d'effroi,

(42) Prévoyant notamment la présence obligatoire d'un a défenseur officicux "

(43) Code pénal de 1791 revu en 1795 art. 612 et 613 . En attendant l'abolition de la peine de mort et son remplacement par une peine de 20 ans de fer.

(44) Bernard SchNaPper, "De Thurmidor à Bonaparte ", dans Philippe Boucuer, dir., La Révolution de la Justice. Des lois du roi au droit modeme, [Paris]. J.-P. de Monza, 1989, p. 216-271.

(45) Voir Emmanuel BLRGLR, "Lévolution législative de la répression du brigandage du Directoire au Consulat (1795-1801) ", communication au colloque de Toulouse, Brigands et Brigandage Criminalité Violence et Protestation politique vers 1750-vers 1850, 24-25 mai 2007. Je remercie l'auteut de m'avoir autorisé a consulter ce texte inédit.

(46) Sur le banditisme voir Florike Egmond, Banditisme in de Franse Tijd. Profiel van de Grote Nederlandse Bende 1790-1799, Amsterdam, Soest, Bataafsche Leeuw, 1986 [L.e banditisme à l'époque française. Profil de la grande bande nécrlandaiselet Xavier Roussbaux, "Espaces de désordres, espace d'ordre : le banditisme aux frontières Nord-Est de la France (1700-1810) ", dans Catherinc DENYs, dir., Frontière et criminalité (1715-1815), Arras, Artois Presses Université, 2000), p. 131-174 ; Xavier RoussEAUX, « Brigandage, gendarmeric et justice. Lordre républicain dans les départements du nord de la France et les départements « réuniss » (Belgiquc, Rhénanié) entre Directoire et Consulat (1795-1804) », dans Jean-Pierre JEsSENnE, dir., Du Directoire au Consultat. 3. Brumuire dans l'histoire du lien politique et de IEtat-Nation, Lille, CRHENO, 2001, p. 91-123. 
dit un orateur [...]. Craignez de confier la juridiction civile aux militaires et de rappeler un régime abhorré, avec lequel il faut éviter la ressemblance ${ }^{47}$. Les débats reflètent ces craintes de voir la juridiction militaire devenir celle de tous les citoyens ${ }^{48}$. La loi fut cependant votée par les Cinq-Cents et approuvée par le Conseil des Anciens le 29 nivôse an VI (18 janvier 1798). Ses trois premiers articles élargissent les crimes désormais passibles de la peine de mort :

«Article 1. Les vols commis à force ouverte et par violence sur les routes et voies publiques, ceux commis dans les maisons habitées, avec effraction extérieure ou escalade, seront, à dater de la publication de la présente loi, punis de mort.

Article 2. Ceux qui seront convaincus d'avoir attaqué, sur les routes et voies publiques, soit les voitures publiques de terre ou d'eau, soit les courriers de la poste ou leurs malles, soit les courriers porteurs des dépêches du Gouvernement, ou des Ministres, ou des autorités constitucés ou des Généraux soit les voyageurs seront punis de la même peine, lorsqu'il apparaittra par les circonstances du fait, que ces attaques ont eu lieu dans le dessein d'assassiner ou de voler, ou d'enlever les lettres, papiers, ou dépêches, lors même que l'assassinat, le vol ou l'enlèvement n'auront pas été consommés.

Article 3. Ceux qui seront convaincus de s'être introduits dans des maisons habitées à l'aide d'effraction extérieure ou d'escalade, seront aussi punis de mort lorsqu'il apparaîtra par les circonstances du fait qu'ils avoient le dessein d'assassiner ou de voler, lors même que ces derniers crimes n'auroient pas été consommés ".

Parmi les dispositions controversées, les articles 4 et 5 introduisent le recours aux juridictions militaires. Notons que la loi précise bien qu'il s'agit d'une juridiction spécifique : les conseils de guerre ${ }^{44}$.

«Article 4. Les cas prévus par les articles précédents restent soumis à la compétence des juges ordinaires ; mais lorsque les délits mentionnés dans les mêmes articles auront été commis par un rassemblement de plus de deux personnes, les prévenus, leurs complices, fauteurs et instigateurs seront traduits par devant un conseil de guerre et jugés par lui.

Article 5. Seront aussi jugés par un conseil de guerre ceux qui dans un rassemblement de plus de deux personnes se seront introduits même sans effraction dans la maison d'un citoyen et y auront commis ou tenté d'y

(47) Journal des débats, floréal an VI, p. 154 cité par Thierry LEJEUNE, "Lapplication des lois d'exception ", dans Jean-Pierre ROYER, Renée MARTJNAGE, dir., Influence du modèle judiciaire en Europe sous la Révolution et l'Empire, Lille, Lespace juridique, 1999, p. 151.

(48) Cité par Emmanuel Berger, "Lévolution législative... ", op. cit.

(49) La confusion entre " commission militairc " et " conseil de guerre " ne se manifesta pas seulement aux Cinq-Cents. Elle reste présente dans certaines contributions récentes. 
commettre des vols à force ouverte ou par violence envers des personnes [...] Cette disposition est applicable à leurs complices, fauteurs et instigateurs ».

Larticle 22 prévoyait que la loi ne serait établie que pour une année. Néanmoins, elle fut appliquée jusqu'au 29 nivôse an VIII (19 janvier $1800)^{51}$. Cette loi introduisait une distinction en fonction des circonstances du vol qualifié. Mais comment estimer un " rassemblement de plus de deux personnes » sinon, dans le cas du flagrant délit ? Ce problème est soulevé dans une lettre du commissaire du pouvoir exécutif de Nivelles, département de la Dyle, au ministre de la Justice, qui exprime bien ce désarroi des autorités : « [...] Vous verrez dans quelle situation se trouvent maintenant les fonctionnaires publics n'ayant pour eux aucune sûreté, n'étant nullement secondés, la gendarmerie par sa faiblesse en nombre, écrasée de service [...] ». Le ministre Lambrechts, originaire du même département de la Dyle, rappelle dans sa réponse : " Vous devez faire sentir à vos concitoyens que la sureté des personnes et des propriétés dépend de leur énergie et de la résistance qu'ils opposeront aux projets liberticides des ennemis intérieurs et extérieurs ; je suis persuadé que les généraux employeront dans cette circonstance critique tous les moyens militaires qui dépendront d'eux mais il faut que l'authorité judiciaire les seconde et que le Directeur du Jury ne manque jamais de renvoyer sur votre réquisitoire devant le Conseil de Guerre ceux qui seraient prévenus de quelques uns des délits prévus par la loi du 29 nivôse an VI " $"$.

La loi du 14 fructidor an VII visa à remédier aux formes lentes des " conseils de guerre " en instaurant des " commissions militaires". Néanmoins, l'assemblée refusa de revenir à de telles institutions créées « à la hâte et jugeant à la hâte ", sans garantie pour les civils ${ }^{52}$.

\section{Des juridictions d'exception limitées}

Comme le rappelle le ministre Lambrechts, les suspects arrêtés n'étaient pas déférés immédiatement aux conseils de guerre. Les militaires devaient renvoyer les suspects vers le directeur du jury de leur arrondissement, lequel devait les adresser aux conseils de guerre s'il constatait l'application de la loi du 29 nivôse an VI. Quelques travaux sur les directeurs de jury confirment cette pratique. Ainsi, dans le petit arrondissement rural de Jodoigne, au Sud-Est de la Dyle, le directeur de jury examine de l'an IV à

(50) Par la loi du 29 brumaire an VIII ; en outre l'article 22 de la loi du 29 nivóse an VI précisait que toute procédure commencée avant a l'écoulement de la méme annéc secont terminées d'après les

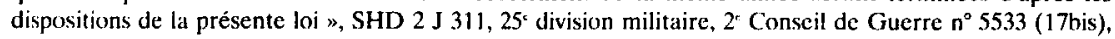
25 frimaire an IX.

(51) AN, BB18/285, Département de la Dyle, Projet de réponse du ministre du 11 thermidor an VII.

(52) Emmanuel Berger, "Lévolution législative... ", op. cit. 
l'an VIII le dossier de 719 personnes ; 11 d'entre elles sont renvoyées devant les conseils de guerre, 7 en l'an VII et 4 en l'an VIII, à l'époque des troubles ${ }^{\text {?3. }}$.

Par arrêté du 13 brumaire an $\mathrm{V}$, dont l'organisation fut plus durable, un conseil de guerre est établi dans chaque division d'armée et dans chaque division territoriale. Chaque conseil comprend sept membres désignés par le commandant de la division : un chef de brigade (colonel), président, un chef de bataillon ou d'escadron, deux capitaines, un lieutenant et un sousofficier. De plus, un capitaine fait fonction de rapporteur de l'affaire et choisit le greffier ; un autre capitaine fait fonction de commissaire du pouvoir exécutif, chargé de veiller à l'observation des formes et à l'application de la loi $^{i 4}$. Ces deux personnages jouaient le rôle le plus important. Ils étaient nommés par le commandant de la division et habitucllement non formés en droit.

Une procédure de révision très rapide était prévue par la loi du 18 vendémiaire an V (9 octobre 1795). Dans les 24 heures, l'affaire était essentiellement réexaminée sous l'angle de la conformité au droit. Le conseil de révision se composait de cinq membres nommés par le commandant en chef de la division (un officier général président, un chef de brigade, un chef de bataillon ou d'escadron, deux capitaines), d'un greffier et d'un commissaire du pouvoir exécutif choisi parmi les commissaires de guerre. Le conseil choisissait un rapporteur en son scin.

Peu de dossiers de procédure ont survécu. Des fragments ont parfois été conservés dans les dépôts locaux (provinces et communes en Belgique, départements en France, au Luxembourg). Seules les procédures renvoyées par les conseils aux juridictions ordinaires peuvent être retrouvées dans les archives des tribunaux criminels. Les registres de jugements, qui devaient exister dans chaque division militaire n'ont, à notre connaissance, pas été conservés au niveau central. Ils existaient cependant : pour la $24^{\circ}$ division militaire par exemple, quelques-uns ont survécu dans les archives de la ville de Bruxelles ${ }^{45}$.

Notre analyse repose essentiellement sur des séries importantes conservées au dépôt de Vincennes. Il s'agit de copies de jugements des conseils de guerre et des conseils de révision expédiées au ministre de la

(53) Nicolas Delvax, L'activité pénale dans l'arrondissement de Jodoigne sous le Directoire : société rurale êt justice nouvelle, Louvain-la-Neuve, 1996, p. 125, 129 (Université catholique de Louvain, mémoire de licence en histoire inédit).

(54) Prosper Pouletet, Les institutions françaises de 1795 à 1814. Essai sur l'origine des institutions belges contemporaines, Bruxelles, 1907, p. 133-142. Malgré son approche téléologique fondée uniquement sur les textes normatifs, l'auteur décrit avec précision les institutions du Directoire, du Consulat ct de l'Empire.

(55) AV Bruxelles, 2883-6, 2887, registres $n^{\circ} 4,5,7$ et 8 de la $24^{\star}$ division militaire, 2885 contrôle général (ans VI et VII). Ils ont fait l'objet d'une analyse dans Jacques BoONE, "In naam,... ", op. cit., II, 2005 , p. 82-98. 
Guerre par les commandants de chaque division militaire. Les jugements sont groupés par juridiction militaire et par date de réception. Les juridictions militaires qui ont jugé le gros des révoltés «belges " furent les divisions installées à Bruxelles (24" division militaire) et à Liège (25" division militaire), capitales des deux anciens ensembles politiques (Pays-Bas autrichiens et Principauté de Liège). La $24^{*}$ division avait juridiction sur les départements occidentaux : les Deux-Nèthes (Anvers), l'Escaut (Gand), la Dyle (Bruxelles) et Jemappes (Mons). La $25^{\circ}$ division militaire était compétente pour les départements orientaux : l'Ourthe (Liège), Sambre-etMeuse (Namur) et la Meuse-inférieure (Maastricht). La Lys (Bruges) relevait de la $16^{\mathrm{c}}$ division militaire (Lille) et les Forêts (Luxembourg) de la $3^{\mathrm{e}}$ division militaire de $\mathrm{Metz}^{56}$.

Les jugements sont conservés dans une quinzaine de boîtes, sommairement classées par ordre chronologique ${ }^{57}$. Ces copies se présentent de la manière suivante. Une lettre d'envoi venant du conseil au ministre de la Guerre enserrant l'ensemble des copies $^{58}$ et donnant parfois quelques précisions complémentaires. Les jugements ont la forme d'un cahier de plusieurs pages, signé par les membres du conseil. Certains jugements portent l'indication d'un pourvoi en révision par le condamné et en marge la notification du résultat du pourvoi et de l'éventuelle exćcution de la sanction.

Identifier les « civils » jugés par les conseils de guerre est une opération complexe. Si dans le cas de prévenus de sexe féminin la frontière entre civils et militaires est nette, il n'en va pas de même pour les révoltés originaires des départements belges, surtout lorsqu'ils ont l'âge de la conscription... Le critère de sélection a donc été le dispositif législatif en vertu duquel les juridictions militaires sont compétentes pour juger des civils.

Pour constituer notre base de données, une série d'informations ont été relevées systématiquement : date du jugement, juridiction, lieu du jugement, nom, prénoms, profession, lieu de naissance, domicile, âge de l'inculpé, noms des parents, préventions, présence d'un interprète et d'un « défenseur officieux », questions posées aux membres du conseil,

(56) Theo VAN DER BEeK, J.GRAuwels, De Boerenkrijg in het departement van de Nedermaas, Anciens Pays et Assemblées d'États, t. 23, 1961 [La guerre des paysans dans le département de la Mcuseinférieure].

(57) Lors de notre première mission en 1993, l'ensemble des cartons ne faisait l'objet d'aucun inventaire. Depuis 1997, un inventaire dactylographié a été réalisé. Le dépouillement s'est effectué en plusicurs étapes en 1993, 1997, pour être achevé en 2000-2001, grâce à l'aide d'Émmanuel Berger, alors licencié en histoire, que je remercie bien vivement.

(58) Dans certains cartons de la 24. DM, en dépit des règles archivistiques, on a procédé à la séparation des jugements de lcur lettre d'envoi. Pire, on a reclassé les jugements en fonction de critères - pas très cohérents - de " nature d'infraction " et de décision (acquittement et condamnation). Ce reclassement effectué entre notre première et notre deuxième visite s'est révélé désastreux pour l'analyse. 
réponses, décision, peine, article de lois invoqués et, en cas d'existence d'une procédure de révision : date, juridiction, lieu et décision.

\section{Procédure et fonctionnement des conseils de guerre}

Si le Directoire avait envisagé de créer des commissions militaires pour juger les chefs de la révolte, dès le 4 novembre 1798, ordre est donné de stopper toutes ces procédures et de les transférer aux conseils de guerre existants $^{59}$. En fonction des événements, de l'an IV à l'an XII, les conseils de guerre siégèrent dans des lieux différents. Pour la $24^{\circ}$ division militaire, le siège du premier conseil était à Bruxelles mais il se déplaça parfois à Gand, voire à Bruges, tandis qu'un second conseil permanent siégea successivement à Bruges, Tournai et Gand ${ }^{(s)}$. Pour la $25^{\circ}$ division militaire, le siège était à Liège, tandis que le second conseil siégea à Luxembourg. Les deux conseils de révision siégeaient à Bruxelles et à Liège.

Les jugements sont assez stéréotypés. Certains ont été étudiés et publiés comme celui de deux mencurs de la révolte dans la région de Turnhout (Deux-Nèthes)" $)^{\prime \prime}$. Le cas de Jean-Baptiste Mibus est éclairant ; il sera jugé trois fois par une juridiction militaire. Le 19 thermidor an VII, le $1^{\text {er }}$ conseil de guerre de la $24^{c}$ division militaire est réuni à Gand sous la présidence du chef de brigade Rigau pour juger René Antoine van Mol, Jean-Baptiste Mibus et Guillaume Labaisse, les deux derniers contumax. Tous trois sont à l'unanimité condamnés à la peine de mort " pour vols commis a force ouverte et violence envers les personnes dans différentes maisons dans le courant du mois de nivôse ». Le jugement de van Mol est confirmé par le conseil de révision siégeant à Bruxelles le 27 thermidor $^{62}$.

Lannée suivante, Mibus est capturé. Le 17 germinal an VIII, il est rejugé par le premier conseil de la $24^{\circ}$ division militaire siégeant cette fois à Bruxelles sous la présidence du chef de brigade Sergent. Après avoir ouvert la séance, le président fait apporter un excmplaire de la loi du 13 brumaire et demande au rapporteur lecture " du procès-verbal d'information et de toutes les pièces tant à charge qu'à décharge envers l'accusé, au nombre de vingt-six ». Ensuite seulement comparaît l'accusé : «Introduit libre et sans fers devant le conseil, accompagné de son défenseur officieux "; il est " interrogé sur ses noms, prénoms, âge, profession, lieu de naissance et domicile ». Il répond s'appeler « Jean-Baptiste Mibus, journalier de 31 ans, domicilié à Melin, canton de Jodoigne, département de la Dyle », avant de s'entendre signifier l'accusation d'avoir participé à l'assassinat des citoyens

(59) Voir Jacques BOONE, " In naam... ", op. cit., II, 2005, p. 60-61.

(60) Ihid., p. 87

(61) lbid., p. 114-123.

(62) SHD, 2 J 296, Jugement du premier conseil de guerre de la 24· DM $n^{\circ} 18862$ confirmé par le Conseil permanent de révision de la $24^{\circ} \mathrm{DM}$. 
Barbare et Carlier le 2 nivôse an VII dans la forêt de Mollendael sous Bierbeek, d'instigations envers le nommé Guillaume Labaisse dans la journée du 3 nivôse an VII en l'armant d'une carabine... et en l'entraînant avec lui et ses complices, ainsi que de cinq vols commis à Gobertange, Melin et Lathuy.

Après l'interrogatoire vient l'audition du rapporteur puis les observations de la défense. Ensuite, après avoir demandé aux membres du conseil leurs éventuelles observations et constaté leur réponse négative, le président prie l'accusé et son défenseur de se retirer pendant la délibération des juges. Reconnu à l'unanimité coupable de l'instigation et de quatre des vols $s^{t^{31}}$, il est condamné à mort " conformément aux articles 5 et 6 de la loi du 29 nivôse an 6, prorogée par celle du 29 brumaire an 7 ». Le président ordonne l'impression du jugement en 300 exemplaires dans les deux langues française et flamande et enjoint au capitaine rapporteur de lire le jugement au condamné : «À sept heures du soir, jour et date que dessus, il a été donné au condamné Mibus lecture du présent jugement en présence de la garde assemblée sous les armes, il lui a aussi été donné connaissance des dispositions de la loi du 13 brumaire an 6 concernant les délais de pourvoi en révision ». Porté en révision par le condamné, le jugement est confirmé le 23 germinal an VIII et « en conséquence a reçu son entière exécution, Mibus ayant été décolé le 29 germinal an $8{ }^{\text {ith }}$. Ce que confirment les archives bruxelloises, témoignant que Mibus fut exécuté le 7 avril $1800^{65}$.

Cette affaire synthétise nombre de caractéristiques de la procédure devant le conseil de guerre. Un formalisme offrant des garanties apparentes à l'accusé : existence de la loi, vérification de la composition du conseil, interrogatoire de l'accusé en présence d'un défenseur officieux et éventuellement d'un interprète, délibération à la majorité, en commençant par le grade inférieur, sur la culpabilité dans chaque chef d'accusation et sur la peine, comme sur d'éventuelles circonstances atténuantes, publicité orale et écrite de la décision, information sur la procédure de révision.

En réalité, ce libéralisme de façade masque une gestion militaire du procès. Ni l'accusé ni son défenseur n'ont connaissance des preuves avant l'audience, tandis que les témoins sont rarement entendus. Certaines étapes se font en dehors de la présence de l'accusé et de son conseil : rapport préliminaire, remarques du conseil, réquisitoire du capitainecommissaire, verdict et sentence. Enfin, la présence du capitaine-commissaire au moment du délibéré constituait une importante limite à l'indépendance du conseil. Dans la pratique, on remarque également que

(63) Mais pas d'un cinquième vol commis chez Marie-Josèphe Gilson, meunière à Schoor.

(64) SHD, 2 J 299, Jugement du premier conseil de guerre de la 24 DM, n 28310.

(65) AE Anderlecht, Archives des tribunaux criminels de la Dyle et de la cour d'assises de Brabant, Procès-verbaux des expositions, $n^{\circ} 203$. 
les juges ne posent que peu de questions à l'accusé, se soumettent à l'avis du rapporteur et du président. Quant à l'accusé, il est informé du verdict dans une cérémonie militaire. Quant à la procédure en révision, elle se borne généralement à constater la légalité de la procédure.

En matière judiciaire, il n'est guère fréquent que les pratiques des acteurs soient commentées par ceux-ci. Pourtant, grâce à une lettre du brigadier général Lacoste, président du second conseil de guerre de la $24^{c}$ division militaire adressée au ministre de la Justice Lambrechts, les obstacles, les freins mais également les scrupules des juges militaires sortent de l'ombre. Chargé de juger les survivants du combat final de la " guerre des paysans ", la prise d'Hasselt (Meuse-Inférieure), parmi lesquels Antoine Constant présumé chef principal de la révolte, Lacoste s'adresse au ministre pour lui poser une série de questions. Derrière celles-ci, c'est davantage un témoignage sur les difficultés de sa mission, et parfois même des considérations sur le sens de celle-ci qui s'expriment.

Le premier objet de sa plainte est la difficulté de juger les coaccusés d'un procès, jamais déférés tous ensemble devant son conseil. Les raisons en sont multiples : l'éloignement de la prison, les problèmes d'identification des civils, l'ignorance linguistique des militaires. La nécessité de copier les interrogatoires et de les traduire en français entraîne frais et retard. Quant aux exécutions, la distance entre le tribunal (Tournai) ou le bourreau (à Mons) renforce l'arriéré. Il faut en effet trois jours pour une exécution qui nécessite la présence d'un juge sur place. Ensuite, curieusement Lacoste évoque de manière à peine voilée sa conception de la justice militaire au ministre. " Dans la chaleur et aux milieux du hazard d'un combat on tue des hommes sans compter, mais la plume à la main, c'est tout autre chose ». Il est particulièrement perturbé par un point précis. Après la prise d'Hasselt, 81 individus ont été arrêtés comme " meneurs de la révolte ", parmi lesquels Antoine Constant. Dans une lettre, un officier et 18 volontaires de la $66^{\circ}$ brigade, faits prisonniers durant les troubles et libérés à la prise d'Hasselt certifient que les 81 individus « dénommés dans le présent contrôle ont été pris les armes à la main " $"$. Or Lacoste, qui a manifestement participé à l'assaut décrit la confusion régnant lors de la bataille.

« Il n'est pas du tout exact de dire que ces brigands ont été pris les armes à la main.

On a tué dans la campagne lors de l'affaire sans miséricorde tout ce qui s'y est trouvé [....] Puisqu'on a relaché et réduit successivement à 81 le nombre des prétendus pris les armes à la main qui d'abord étoient beaucoup au-delà de cent ainsi le nombre des hommes pris réellement les armes à la main a été de huit à douze sur le champ de bataille au rapport du comman- 
dant de l'escadron (ici présent) et celuy des hommes pris en ville en cet état a été et est réellement très incertain.

[Il en conclut :] Des prisonniers qui sont restés deux ou trois jours avec quatre à cinq mille brigands ont bien pu avoir occasion de reconnaître leurs chefs, mais comment pouvoir dire d'un nombre déterminé et considérable la meme chose, et assurer qu'il n'y ait point d'innocent.

Une autre remarque bien essentielle c'est que ce n'est pas sur le lieu meme à Hasseld que ce controlle de 81 a étć signé mais huit jours après à Bruxelles ou très vraisemblablement aucun signataire n'est allé aux prisons reconnoitre l'identité des 81 individus ».

Militaire, l'officier est un juge républicain qui veut appliquer la loi à la lettre. Il exprime au ministre toute sa méfiance envers un document qui assimile aux meneurs les rares survivants d'un massacre... Plus que bien des réflexions théoriques, Lacoste rappelle que les pratiques militaires peuvent être contradictoires avec les exigences de la justice et souligne que le métier des militaires est de faire la guerre, mais pas de rendre la justice.

Deux politiques criminelles. Deux catégories de civils : « rebelles » et brigands

Une autre manière de saisir l'activité de la justice envers les civils est d'en étudier l'ampleur. L'enseignement majeur de l'analyse quantitative de la pratique des quatre conseils est l'existence d'une double politique criminelle ${ }^{67}$, menée par les conseils de guerre et de révision des deux divisions militaires.

(67) Sur la politique pénale de la Révolution voir Xavier RousSEauX, "Politique judiciaire, criminalisation et répression. La révolution des juridictions criminelles (1792-1800) ", dans Jean-Clément MARTIN, dir., La Révolution française à l'áuvre. Perspectives actuelles dans l'histoire de la Révolution française, Rennes, PUR, 2005, p. 89-114. 
Figure 1 : Les accusations contre les civils jugés par les conseils de guerre des $24^{\circ}$ et $25^{\circ}$ divisions militaires

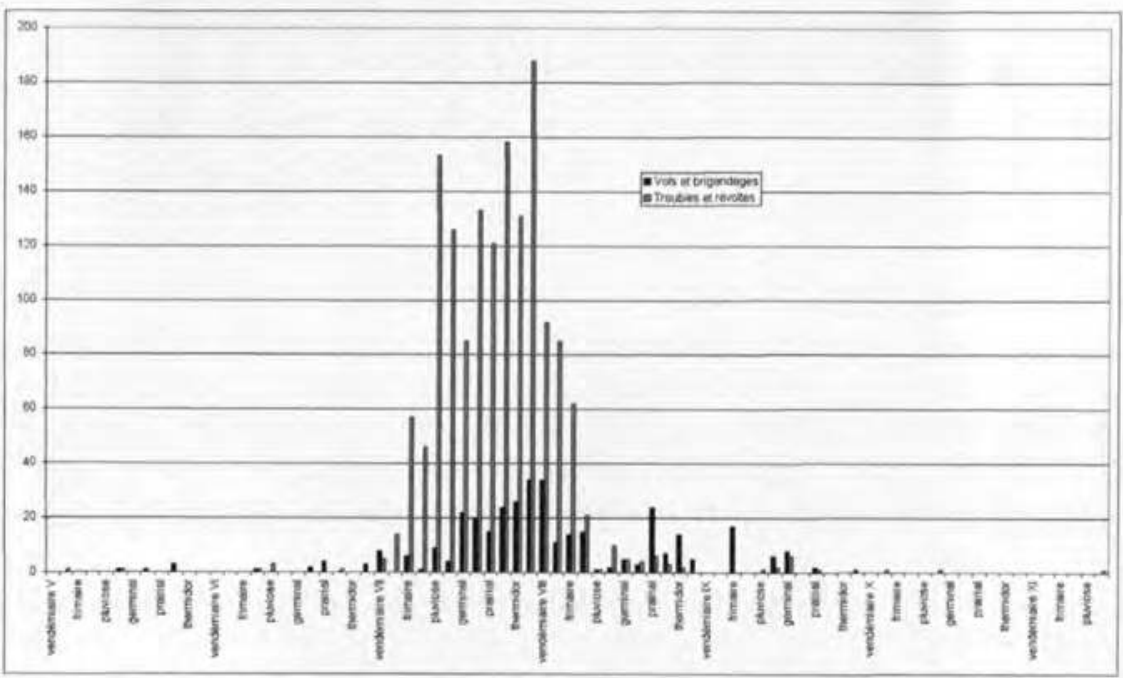

La première vise à traiter juridiquement le sort des révoltés saisis les armes à la main lors des conflits d'octobre-décembre 1798. La seconde, antérieure, consiste à suppléer les juridictions ordinaires (tribunaux correctionnels et criminels) jugés trop soumis aux contraintes locales, dans la lutte contre un brigandage parfois perçu comme une résistance à l'occupant.

Figure 2 : Typologie des civils jugés par les conseils de guerre des $24^{\text {e }}$ et $25^{\circ}$ divisions militaires

\begin{tabular}{|l|l|l|l|l|}
\hline & $24^{e} \mathrm{DM}$ & $25^{\mathrm{e}} \mathrm{DM}$ & Total & $\%$ \\
Voleurs et brigands & $\mathbf{2 5 1}$ & $\mathbf{9 5}$ & $\mathbf{3 4 6}$ & $\mathbf{1 8}$ \\
\hline Révoltés & $\mathbf{1 3 5 0}$ & $\mathbf{1 7 8}$ & $\mathbf{1 5 2 8}$ & $\mathbf{7 9}$ \\
\hline Divers & $\mathbf{1 5}$ & $\mathbf{5 0}$ & $\mathbf{6 5}$ & $\mathbf{3}$ \\
\hline Indéterminé & $\mathbf{0}$ & $\mathbf{5}$ & $\mathbf{5}$ & $\mathbf{0}$ \\
\hline Total & $\mathbf{1 6 1 6}$ & $\mathbf{3 2 8}$ & $\mathbf{1 9 4 4}$ & $\mathbf{1 0 0}$ \\
\hline
\end{tabular}

En regroupant les individus en deux grandes catégories : troubles et révoltes, vols et brigandages, nous observons que près de 2000 civils ont été jugés durant cette période. La grande majorité sont des hommes; on ne compte que 75 femmes, soit moins de $4 \%$ des accusés. Abstraction faite de cas litigieux (déserteurs autrichiens, recruteurs, conscrits non encore incor- 
porés), près de $80 \%$ d'entre deux furent jugés pour faits de révolte, $18 \%$ pour vol avec violence et brigandage.

Une certaine cohérence se marque dans l'analyse des décisions. Tant dans la $24^{\circ}$ que dans la $25^{\circ}$ division militaire, la majorité des peines de détention et de mort furent prononcées par le premier conseil, tandis que le second prononça la majorité des acquittements. En ce qui concerne les rebelles, dans les deux divisions, 50 à $60 \%$ des jugements prononcent l'acquittement, 20 à $25 \%$ des peines de détention courtes et 15 à $25 \%$ la peine de mort. En revanche, les juges sont nettement plus sévères pour les brigands. Ces derniers sont rarement condamnés à la détention ( 2 fois sur 10 ), mais acquittés dans 4 cas sur 10 et condamnés à mort dans 4 autres cas. Les dix-neuf femmes poursuivies pour participation à la révolte ${ }^{68}$ sont toutes acquittées, à l'exception d'Anne Philips Verdievelde, condamnée à quatre mois de détention pour participation à un rassemblement séditieux à Hooglede ${ }^{69}$. Les cinquante-six autres femmes sont jugées pour brigandage. Elles subiront des peines sévères et certaines n'échapperont pas à la mort.

Examiné globalement, le sort des accusés varie selon qu'ils sont jugés comme « rebelles » ou comme brigands. Du côté des rebelles, près de 900 individus furent acquittés. Certains font l'objet d'un acquittement conditionnel. Les mineurs sont renvoyés à leurs parents ou en maison de correction, les conscrits et les déserteurs autrichiens sont envoyés dans les dépôts qui les regroupent. La grande majorité des rebelles sont condamnés à une peine de détention courte : un à quatre mois de détention. 414 hommes et une femme sont condamnés en vertu de l'article 5 de la loi du 30 prairial an III à une peine généralement de quatre mois de détention, à partir de la date de leur arrestation ${ }^{70}$. Cette peine est assortie d'une amende sévère, la moitié du revenu annuel. 208 accusés sont condamnés à mort. Aucun révolté n'est condamné à une peine d'emprisonnement criminel, celle-ci étant réservée aux déserteurs ou aux voleurs. Il en va tout autrement des brigands. Remarquons tout d'abord le faible nombre de jugements des conseils de guerre en l'an V et VI, malgré les lois de floréal an V et nivôse an VI. Ce n'est qu'avec le déclenchement des troubles au début de l'an VII que les arrestations de brigands vont se multiplier. Le profil répressif, on l'a vu, est plus accusé : 346 «brigands » dont une trentaine de femmes furent jugés pour banditisme, 125 d'entre eux dont trois femmes furent condamnés à mort, 20 autres à des peines de détention criminelle de plusieurs années soit $40 \%$ des prévenus. Le reste fut acquitté.

(68) 18 par les conseits de la 24" DM, 1 seule dans la 25" DM.

(69) SHD 2 J 298, 24 $4^{\circ}$ DM, 2 Jugement du second conseil de guerre, $n^{\circ} 17221$

(70) 351 dans la $24^{\circ} \mathrm{DM}$ et 34 dans la $25^{\circ} \mathrm{DM}$. 
Si l'on s'en tient aux jugements les plus sévères, la chronologie des condamnations à mort prononcées par les quatre conseils militaires confirme tout à la fois la liaison des deux mouvements répressifs et le léger décalage entre les pics de la répression envers les révoltés et les brigands.

Figure 3 : Les civils condamnés à mort par les conseils de guerre des $24^{\circ}$ et $25^{\circ}$ divisions militaires

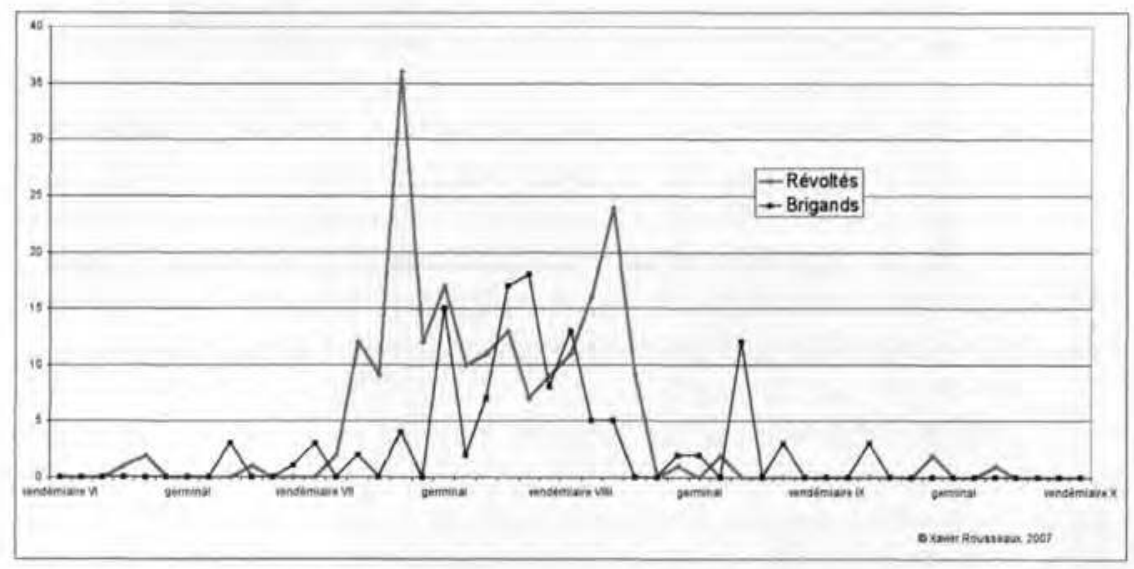

En se limitant aux condamnés à mort, le décalage est plus net entre les deux pics de condamnation envers les meneurs des révoltes (brumaire an VII à nivôse an VIII) et la majorité des condamnations pour brigandage (germinal an VII à frimaire an VIII, prairial an VIII). Lactivité des conseils de guerre des $24^{e}$ et $25^{\text {e }}$ divisions militaires présente des caractéristiques très marquées. En ce qui concerne les révoltés, une première vague de condamnations suit les combats et concerne ceux qui furent capturés sur le champ ; une seconde vague intervient après enquête et capture des échappés. Pour les brigands, les condamnations sont plus régulières, mais les opérations militaires consécutives à la réforme permirent sans doute de démanteler une série de petits groupes de chauffeurs et garrotteurs. Preuve en est donnée par le décalage plus important entre les dates des crimes suspectés pour les brigands et celles des événements séditieux.

Alors, l'utilisation du terme brigand est-il une manœuvre de disqualification des révoltés (résistants) par la Convention puis le Directoire ? $\mathrm{Ou}$, au contraire, le brigandage traditionnel a-t-il servi de terreau organisationnel à la révolte " politique " et religieuse ? Dans le chef des juges militaires, les choses semblent assez claires. Du côté des révoltés, en application de la loi du 30 prairial an III, seuls les chefs sont condamnés à mort, les suiveurs condamnés à 4 mois de détention ou acquittés. Quant aux brigands, ils subissent des peines criminelles (mort ou travaux forcés, réclu- 
sion), pour des comportements précisés par les lois de floréal an $\mathrm{V}$ et nivôse an VI. Ces peines sont éventuellement modérées pour le jeune âge (enfermement en maison de correction), selon le Code pénal.

Enfin, le traitement des femmes par la justice militaire est différencié. Quasi systématiquement acquittées en cas de participation aux révoltes, elles sont durement frappées lorsqu'elles sont convaincues de prêter main forte aux chauffeurs (comme receleuses par exemple).

\section{Justice militaire et justice civile : concurrence ou complémentarité ?}

Si lors de la conquête militaire, les tribunaux criminels peuvent juger révolutionnairement des civils motu proprio et les exécuter par fusillade, ils les renvoyaient souvent devant les institutions civiles. D'autre part, on a observé combien l'établissement de commissions et de conseils militaires dans les départements belges fit l'objet de débats serrés entre les autorités militaires, les autorités judiciaires locales et le ministre de la Justice.

Au moins sur le papier, à partir de la loi du 29 nivôse an VI, le recours aux conseils de guerre supposait au début comme à la fin de la procédure l'intervention des autorités civiles, en l'occurrence le directeur du jury d'arrondissement. Dans la pratique, les conseils de guerre des deux divisions militaires renvoient une cinquantaine de prévenus devant d'autres juridictions. Soit que les tribunaux militaires ne sont pas compétents mais bien les juridictions ordinaires, soit que la procédure qui prévoit une décision de compétence par le directeur du jury du domicile du prévenu n'a pas été respectée. Par exemple, trois individus suspects d'avoir arraché des cocardes nationales à différents particuliers, poussé des cris séditieux et chanté une chanson tendant à l'avilissement de la République sont renvoyés au tribunal criminel de la Lys sur réquisitoire du commissaire du pouvoir exécutif en vertu de l'art 1 et 2 de la loi du $1^{\text {tr }}$ germinal an III ${ }^{71}$.

Les scrupules judiciaires des juges militaires sont poussés très avant, notamment quant à connaître le statut de l'individu - civil ou militaire-, ou à savoir si le directeur du jury avait bien renvoyé l'affaire devant le conseil de guerre avant l'expiration de la loi. C'est le cas dans une affaire où, après consultation du ministre de la Justice, le second conseil de guerre de la $25^{\mathrm{c}}$ division militaire se déclare incompétent pour juger un déserteur prévenu de délits selon la loi du 29 nivôse an VI, qui a été renvoyé par le directeur du jury de Hasselt au conseil de guerre, au motif que le renvoi est postérieur à l'expiration de la loi' . 
À la fin de la procédure, l'exécution des peines, prévues par le Code pénal, impliquait la collaboration des autorités civiles. Ainsi à Bruxelles, une quarantaine de civils sont « décolés » sur la grand'place de la ville suite à jugement militaire durant les troubles ${ }^{73}$. Sept d'entre eux pour assassinat, les autres pour vol, rassemblement contre la république ou brigandage, à l'instar de Jean Mibus, exécuté le 7 avril $1800^{74}$. Le mode d'exécution était cependant l'objet d'appréciations différentes, surtout au début de l'annexion. Ainsi pour le substitut du commissaire du pouvoir exécutif du tribunal criminel de la Dyle, « les malveillans dans nos neuf departements [...] prêchent pour la fusillade et s'agitent pour faire proscrire la guillotine. Ils craignent et redoutent (disent-ils) même l'ombre comme instrument et emblème de la terreur, lorsque sous leurs dehors mielleux, ils prechent l'anarchie, le fanatisme, le pillage, l'assassinat et méditent ainsi qu'ils menaçent les Républicains et les Belges attachés à notre gouvernement du

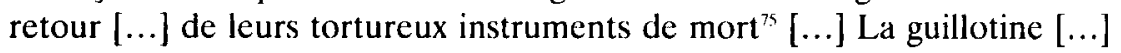
contiendra tous les faux amis de l'ordre, nos ennemis les plus cruels». Il était donc important que l'exécution des sentences de mort des commissions militaires et des conseils de guerre envers les civils s'exercent par guillotine et non par fusillade, perçue comme l'expression d'une occupation militaire.

Dans les neuf départements réunis, la question de l'ordre public était partiellement semblable à celle des grandes aires de dissidence de la France de l'Ouest ou du Midi. Les juges de paix et les directeurs de jury hésitaient à entamer des poursuites contre les auteurs de vols en bande, les tribunaux criminels ordinaires acquittaient systématiquement tous ceux qui pouvaient être perçus par une partie de la population comme opposants au régime. À la différence de l'Ouest ou du Midi, cependant, tout Français " de nation ou d'opinion " était perçu comme un occupant étranger par une partie de la population, notamment dans les campagnes. Convention et Directoire purent cependant comme dans les départements métropolitains rétablir un réel ordre public. Les révoltes de l'an VII justifièrent l'intervention de l'armée, qui en profita non seulement pour éliminer les foyers de révolte mais pour démanteler les réseaux de " chauffeurs " et "garrotteurs". Les conseils de guerre furent les vecteurs principaux de la répression, laissant aux tribunaux criminels le jugement de crimes plus ordinaires (vols et

(73) Laurence Gerlung, La guillotine, le carcan et la marque. Etude des exécutions publiques dans le département de la Dyle pendant la période françatise (1796-1813), Louvain-la-Neuve, 2007, p. 145-148 (Université catholique de Louvain, mémoire de licence en histoire inédit).

(74) AE Anderlecht, Archives des tribunaux criminels de la Dyle et de la cour d'assises de Brabant, Procès-verbaux des expositions, $\mathrm{n}^{\circ} 203$.

(75) AN, BB18/283, lettre du substitut du commissaire du pouvoir exécutif Champré au ministre de la Justice, 26 nivôse an IV. 
violences commises à moins de trois personnes). Pour cette raison, à la différence de la Provence, il ne fallut pas recourir à des commissions militaires supplémentaires pour rendre à la République la maitrise de l'espace public ${ }^{76}$. Si les assemblées du Directoire acceptèrent de voter la loi des otages le 24 messidor an VI, en revanche, elles refusèrent de recourir à des commissions militaires spéciales, préférant multiplier les conseils de guerre pour juger les nombreux suspects arrêtés"

Après nivôse an VIII, l'activité des conseils des $24^{\circ}$ et $25^{\circ}$ divisions militaires envers les civils décroît fortement. Néanmoins, on trouve des affaires jugées jusqu'en l'an XII, généralement pour des faits commis avant l'an IX. C'est qu'entre-temps, la législation a changé. Plutôt que de confier à des juridictions militaires le jugement de civils, le gouvernement du Consulat préfère désormais introduire des militaires dans des juridictions civiles. Ce seront les tribunaux spéciaux instaurés par la loi du 18 pluviôse an IX. Aux côtés du président et de deux juges du tribunal criminel, siégeront trois militaires et deux civils (généralement des défenseurs officieux). Ceux-ci jugeront sans jury et sans cassation possible des catégories plus larges de civils (mendiants, vagabonds, chauffeurs et brigands) perçues comme une menace pour la cohésion sociale et la légitimité de l'État ${ }^{78}$. Quelques jours plus tard, le 26 pluviôse an IX, Regnaud de Saint-Jeand'Angély écrit à propos de la 24 e division : " [...] Sur un territoire immense et une population de près de trois millions d'habitants, il n'y a pas plus d'un bataillon de troupes de ligne qui n'est occupé que du service de quelques postes militaires, et que la gendarmerie suffit pour maintenir la plus profonde tranquillité " $"$. Son collègue Redon pour la $25^{\circ}$ division signale « ces départements, qui ne sont pas tout-à-fait à l'abri du brigandage, peuvent cependant être placés au nombre de ceux où la sûreté des personnes et des propriétés est le plus rarement compromise $»^{k 10}$. Derrière la mise en scène des rapports ordonnés par le gouvernement consulaire, on remarque qu'à la différence de la période précédente, le brigandage n'est plus mis en évidence comme le problème majeur de l'ordre public.

(76) Stephen Clay, " Le brigandage en Provence du Directoire au Consulat ", dans Jean-Pierre Jessenne, dir., Du Directoire au Consultat. 3. Brumaire dans l'histoire du lien politique et de l'Élat-Nation, Lille, CRHENO, 20(01, p. 67-89.

(77) Howard BRown, Ending the French Revolution..., op. cit., p. 228-229.

(78) Dominique Bouguer, "Une juridiction d'exception : le tribunal criminel spécial d'Indre-etLoire (an IX-1811) ", Histoire de la justice, 1994, 7, p. 89-116; Gilles LANDRON, " Les tribunaux criminels spéciaux contre les tribunaux criminels avec jury (France, an IX - 1811) ", dans Xavier Rousseaux, MarieSylvie Dupont-Bouchat, Claude VAEL, dir., op. cit., p. 189-198.

(79) Rapport du citoyen Regnaud de Saint-Jcan-d’Angély Conseiller d'État envoyé en mission dans la $24^{c}$ division militaire au mois de pluviôse an IX, cité par Félix RocovaIn, L'état de la france au 18 brumaire d'après les rapports des conseillers d'état chargés d'une enquête sur la situation de la République..., Paris, 1874 , p. 350

(80) Rapport du cituyen Redon, Conseiller d'État envoyé en mission dans la $25^{\circ}$ division militaire au mois de pluviôse an IX, cité par Félix RocouAin, op. cit., p. 344. 
L'exemple des $24^{e}$ et $25^{\circ}$ divisions militaires suggère une nouvelle lecture des rapports noués dans la justice répressive entre liberté (civile) et sécurité (militaire). À côté de l'efficacité répressive, la réticence des militaires à juger des civils est à prendre en compte dans la décision de créer les tribunaux spéciaux de l'an IX.

Xavier RousseauX

FNRS, Université catholique de Louvain-la-Neuve

Centre d'histoire du droit et de la justice rue du Poirier, 10

B-1348 Louvain-la-Neuve

Belgique xavier.rousseaux@uclouvain.be 